\title{
Pengembangan Thermal Barrier Coating (TBC) NiCrAl pada Logam Paduan Berbasis Ni untuk Komponen Turbin Gas
}

\author{
Hubby 'I, ${ }^{*}$ Kusnandar, Toto S., Anggito P.T., Diah I., dan K.A. Zaini T \\ Pusat Penelitian Fisika, LIPI \\ Komplek PUSPIPTEK Serpong, Tangerang 15314
}

\begin{abstract}
Intisari
Adanya faktor pengurangan emisi gas dan peningkatan efisiensi energi mengakibatkan makin banyaknya masalah kerusakan komponen akibat korosi temperatur tinggi. Sementara ini, bahan yang digunakan untuk pelapisan memiliki kandungan yang berbeda dari substratnya, dan ternyata menimbulkan beberapa masalah seperti terbentuknya topologically closed phase (TCP) yang akan menimbulkan retakan, terjadinya delamination dan terbentuknya permukaan lapisan yang tidak rata. Oleh karena itu, pada penelitian ini dikembangkan TBC $\mathrm{NiAl}$ pada substrat berbasis Ni dengan metode gabungan elektroplating dan pack cementation. Penelitian ini terdiri atas deposisi Ni dengan elektroplating dan deposisi Al dengan pack cementation. Setelah itu dilakukan tes oksidasi pada temperatur $1150^{\circ} \mathrm{C}$. Untuk analisa dan karakterisasi interdifusi elemen lapisan dan substrat dilakukan dengan EPMA.
\end{abstract}

KATA KUNCI: Thermal Barrier Coating (TBC), elektroplating, pack cementation, NiAl, logam paduan Ni, turbin gas

\section{PENDAHULUAN}

Ratifikasi Traktat Kyoto tahun 2003 berkaitan dengan keselamatan lingkungan global, menuntut dunia industri untuk mengurangi gas emisi dan meningkatkan efisiensi termal pada mesin jet dan mesin produksi energi listrik. Salah satu cara untuk mengurangi emisi gas beracun seperti gas $\mathrm{CO}_{2}$ adalah dengan meningkatkan temperatur TIT (turbine inlet temperature) turbin gas dari temperatur operasi TIT sekitar 1100$1250^{\circ} \mathrm{C}$ dinaikkan hingga mencapai $1450^{\circ} \mathrm{C}$. Tingginya TIT ini mengakibatkan makin tinggi juga panas yang dialami oleh bahan komponen mesin dan semakin banyak menimbulkan masalah korosi dan kerusakan komponen turbin gas.

Salah satu cara untuk mengatasi tingginya TIT ini adalah mendesain material yang mampu bekerja pada kondisi temperatur tinggi. Sudu-sudu pada turbin gas biasanya dibuat khusus dari paduan super yang berbasiskan nikel dan cobalt, dan mampu beroperasi pada kondisi temperature dan tegangan pada berbagai komponen mesin yang sangat tinggi. Di lain pihak, meski sudah didesain sesuai kondisi yang diinginkan, ternyata hal ini belum cukup. Maka cara yang lain adalah dengan Thermal Barrier Coating (TBC), yang memiliki konduktivitas thermal yang rendah, sebagai penahan pelindung untuk komponen paduan super Ni. Penggunaan TBC akan memungkinkan mesin beroperasi pada temperatur $150-200^{\circ} \mathrm{C}$ lebih tinggi dari temperatur operasi konvensional, di mana permukaaan paduan super tetap dipertahankan di bawah batasan yang aman [1]. Dengan temperatur operasi turbin gas sekarang ini, kegagalan TBC dihasilkan dari

*E-MAIL: hubb001@lipi.go.id, hubbyiz@yahoo. com melelehnya sudu-sudu. Tetapi, meski tidak sampai pada kondisi yang separah itu, sudu-sudu menderita karena terjadinya percepatan oksidasi, yang tergantung lingkungan, dan korosi panas. coating TBC dipertimbangkan mampu menyediakan ketahanan oksidasi/korosi panas pada komponen-komponen ini $[2,3]$.

Sistem TBC ini biasanya terdiri atas lapisan keramik topcoat dan lapisan bond-coat di bagian bawahnya. Keramik top-coat, biasanya berupa yttria stabilized zirconia (YSZ) dan lapisan bond-coat biasanya berupa aluminides (NiAl atau $\mathrm{Ni}_{2} \mathrm{Al}_{3}$ ) dan MCrAlY ( $\mathrm{M}=\mathrm{Ni}$, Co atau $\mathrm{Fe}$ ). Dan sementara ini, bahan yang digunakan untuk pelapisan memiliki kandungan yang berbeda dari substratnya, yakni pada bond coat, di mana hal ini ternyata menimbulkan beberapa masalah yaitu: terbentuknya topologically closed phase (TCP) yang akan menimbulkan retakan, terjadinya delamination dan terbentuknya permukaan lapisan yang tidak rata. Oleh karena itu, pada penelitian ini dikembangkan TBC bond coat NiAl pada substrat berbasis Ni dengan metode gabungan elektroplatingpack cementation.

\section{DASAR TEORI}

Sistem TBC ini biasanya terdiri dari dua lapisan yaitu lapisan keramik top-coat dan lapisan bond-coat di bagian bawahnya. Gambar 1 adalah Ilustrasi tampang lintang Thermal Barrier coating System dan distribusi panas pada komponen lidah turbin gas

Keramik top-coat, biasanya berupa yttria stabilized zirconia (YSZ) yang mempunyai titik leleh tinggi, reaktifitas kimia dan konduktifitas termal yang rendah dan bersifat resistan terhadap serangan oksidasi. Sedangkan lapisan bond-coat bi- 


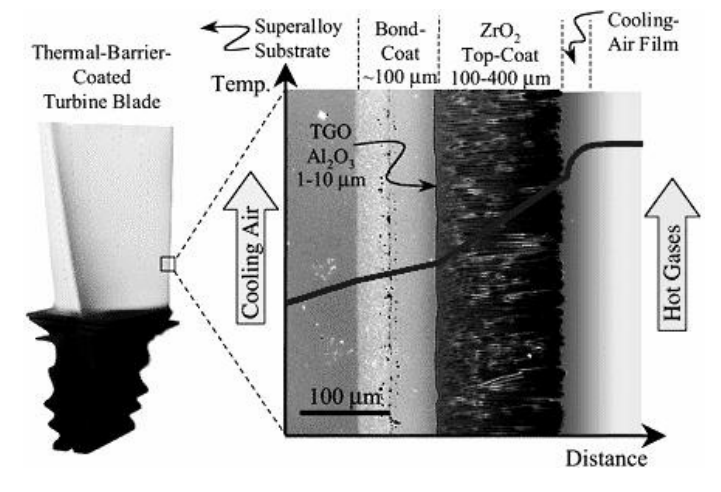

Gambar 1: Ilustrasi tampang lintang Thermal Barrier Coating System dan distribusi panas pada komponen lidah turbin gas

asanya berupa aluminides ( $\mathrm{NiAl}$ atau $\mathrm{Ni}_{2} \mathrm{Al}_{3}$ ) dan MCrAlY $(\mathrm{M}=\mathrm{Ni}, \mathrm{Co}$ atau $\mathrm{Fe})$ yang berfungsi menjembatani perbedaan koefisien termal ekspansi antara lapisan keramik dengan substrat. Selain itu tujuan dari adanya bond coat ini ini adalah: (i) untuk menyediakan penahan permukaan layer keramik, (ii) untuk memberikan proteksi oksidasi terhadap zirconia yang sangat cepat bereaksi terhadap oksigen, dan (iii) untuk menawarkan beberapa ketahanan terhadap bentukbentuk lain korosi yang termasuk oksidasi-sulfidasi dan korosi temperature tinggi (dari adanya deposit cairan alkali sulfate), yang dibutuhkan jika terjadi layer keramik mengalami patahan $[2,3]$. Pack cementation ini dapat digunakan untuk membuat lapisan coaing dengan tebal $>25 \mu \mathrm{m}$ [4].

Disamping itu, selama proses pengoperasian mesin, lapisan bond-coat akan memproduksi scale oksida $\mathrm{Al}_{2} \mathrm{O}_{3}$ atau $\mathrm{Cr}_{2} \mathrm{O}_{3}$ yang bersifat protektif, sekaligus berfungsisebagai perekat antara bond-coat dengan keramik top coat.

Pada penelitian ini digunakan bond coat $\mathrm{NiAl}$ (aluminide), di mana difusinya berdasarkan senyawa intermetallic $\beta-\mathrm{NiAl}$ (lihat diagram fasa pada Gambar 2). Walaupun beberapa proses digunakan untuk membentuk fasa tersebut, tetapi yang banyak digunakan adalah pack cementation, karena tidak membutuhkan biaya yang tidak mahal dan cocok untuk coating komponen-komponen kecil.

Pack cementation merupakan salah satu kategori dari chemical vapor deposition. Dalam proses ini, komponenkomponen yang mau di-coating, dicelupkan ke dalam campuran bubuk yang mengandung partikel-partikel $\mathrm{Al}_{2} \mathrm{O}_{3}$ dan aluminium. Kemudian ammonium halide sebanyak 1-2 wt\% ditambahkan ke dalam "pack" ini. Kemudian dipanaskan sampai sekitar $800-1000^{\circ} \mathrm{C}$ dalam kondisi argon atau $\mathrm{H}_{2}$. Pada temperatur ini, terbentuk aluminium halides yang berdifusi melalui "pack" dan bereaksi pada substrat untuk mendepositkan logam Al. Pemeliharaan aktivitas Al pada permukaan substrat dapat didefinisikan ke dalam dua kategori metode deposisi Al, aktivitas rendah dan tinggi, yang masingmasing dihubungkan terhadap difusi keluar dan ke dalam.

Pada semen dengan kandungan $\mathrm{Al}$ rendah (aktivitas rendah/keluar), pembentukan coating umumnya terjadi oleh difusi Ni, dan hasilnya terbentuk langsung layer NiAl, kaya nikel. Proses ini membutuhkan temperature tinggi (1000$\left.1100^{\circ} \mathrm{C}\right)$. Dalam pemakaiannya, interdifusi dengan substrat
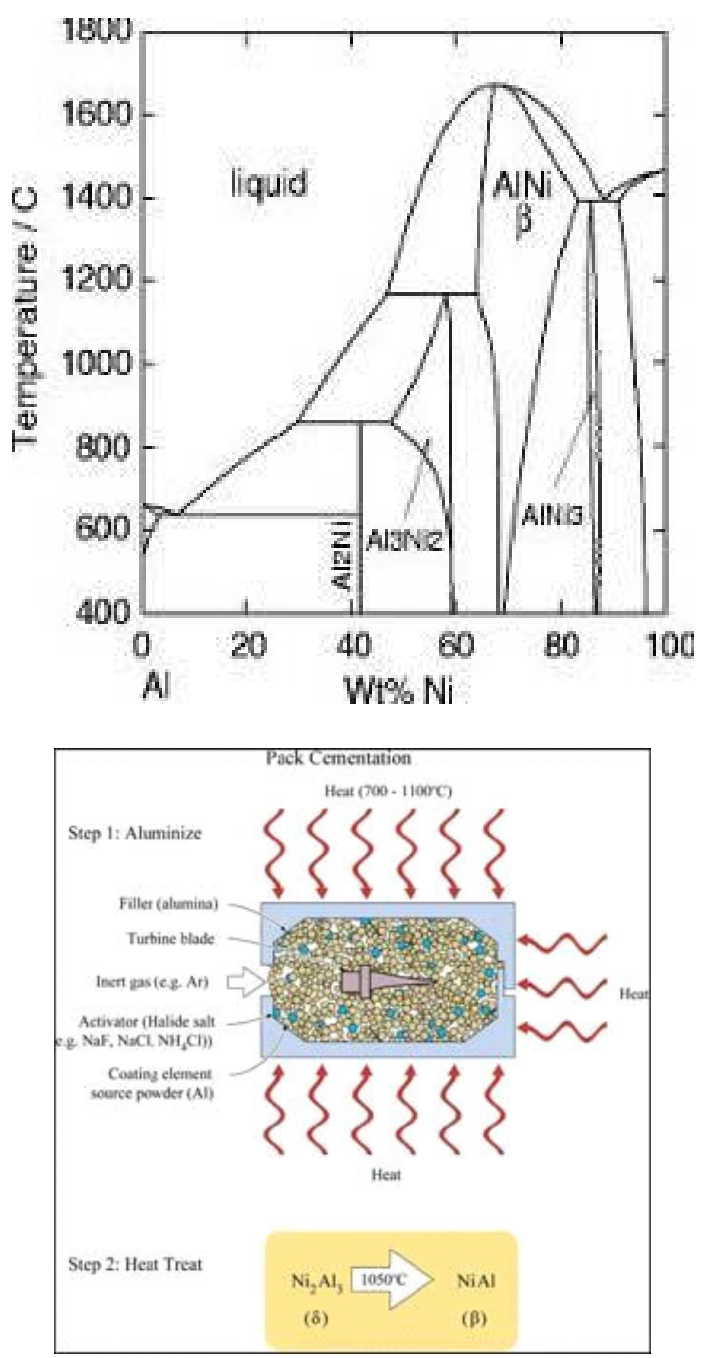

Gambar 2: Diagram fasa Ni-Al (http://www.msm.cam.ac.uk/phasetrans/2003/Superalloys/ coatings/aluminides.html) dan skema ilustrasi proses pack cementation( $\mathrm{Z}$. Yu, dkk, 2005)

sangat dibatasi dan gradient $\mathrm{Al}$ dalam $\beta$ sangat rendah.

Sementara itu, pada semen dengan kandungan $\mathrm{Al}$ yang tinggi (aktiitas tinggi/ke dalam), pembentukan coating umumnya dengan difusi ke dalam oleh Al dan menghasilkan pembentukan $\mathrm{Ni}_{2} \mathrm{Al}_{3}$ dan kemungkinan $\beta$-NiAl. Temperature Aluminizing dapat lebih rendah $\left(700-950^{\circ} \mathrm{C}\right)$, dalam kondisi coating ini gradient konsentrasi Al sangat tinggi, dan juga selama pemakaian interdifusi dengan substrat terjadi signifikan. Oleh karena itu, difusi oleh pemanasan pada umumnya terjadi pada $1050-1100^{\circ} \mathrm{C}$,yang berguna memperoleh lapisan $\beta$ penuh.

Contoh mikrostruktur coating aluminide aktivitas rendah ada pada Gambar 3. Daerah luar berupa kaya Al dari fasa $\beta$-NiAl, sementara di bagian dalam berupa kaya Ni. Untuk deposisi Ni dan Al lapisan banyak, proses pack cementation dilanjutkan dengan pemanasan reaksi-difusi yang selanjutnya digunakan sebagai metode sintesa nickel aluminide thin film [4].

Komponen-komponen mesin panas mengalami degradasi 


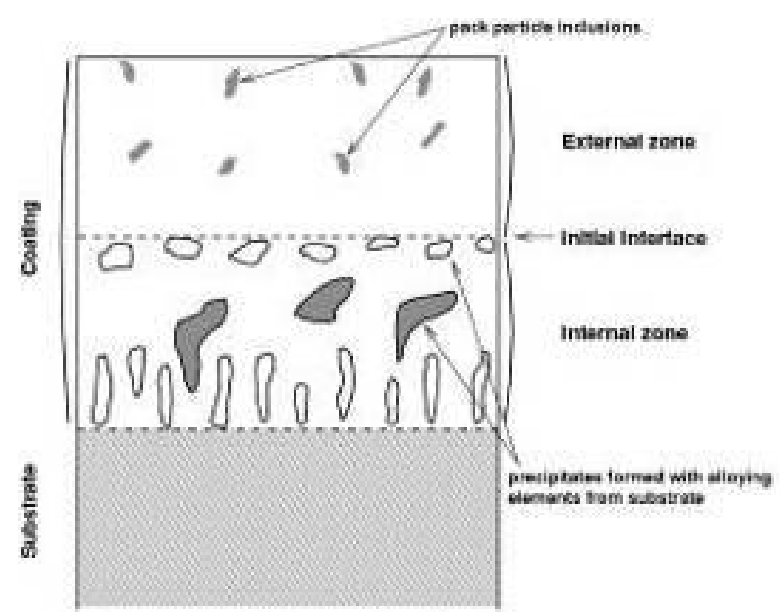

Gambar 3: Ilustrasi skema coating aluminide yang diperoleh dengan pack cementation aktivitas rendah [5]

oleh beberapa mekanisme yang berbeda. Sebagian besar mekanisme yang terjadi selama pemakaian adalah cracking, environmental attack, creep, wear dan metallurgical embrittlement. Cracking terjadi dikarenakan thermal mechanical fatigue dan atau creep, dan dapat juga dibantu oleh environmental attack dan metallurgical embrittement. Environmental attack disebabkan olek oksidasi dan korosi panas, dan mengakibatkan pengikisan permukaan. Environmental attack dapat mengakibatkan patahan logam dalam kombinasi dengan fatigue dan creep. Jenis serangan ini dipertimbangkan sebagai degradasi coating yang utama. Creep merupakan distorsi atau elongasi komponen secara terus menerus, dan mengakibatkan cracking dan atau wear. Metallurgical embrittlement merupakan kehilangan sifat-sifat mekanis yang dikarenakan adanya perubahan metalurgis dalam suatu logam. Wear merupakan degradasi yang diakibatkan oleh kontak antara permukaan dua bahan. Prinsip mekanisme kegagalan dari TBC adalah spallation dari lapisan keramik. Spallation ini disebabkan oleh interaksi sinergi antara oksidasi bond coat dan siklus termal. Oksidasi terjadi pada interface antara bond coat dan lapisan keramik [6].

\section{METODOLOGI PENELITIAN}

Bahan yang digunakan sebagai substrat dalam percobaan ini adalah paduan logam super berbasis Nikel yang banyak digunakan untuk keperluan bahan tempertur tinggi mencapai $1000^{\circ} \mathrm{C}$. Komposisi kimia bahan ini tercantum pada Table 1.

TABEL I: Komposisi Kimia Bahan Sebelum coating

\begin{tabular}{ccccccc}
\hline \hline $\mathrm{Ni}$ & $\mathrm{Al}$ & $\mathrm{Co}$ & $\mathrm{Cr}$ & $\mathrm{W}$ & $\mathrm{Ta}$ & $\mathrm{Ti}$ \\
\hline 62.99 & 12.28 & 9.32 & 9.18 & 3.05 & 1.06 & 0.87 \\
\hline \hline $\mathrm{Hf}$ & $\mathrm{Mo}$ & $\mathrm{C}$ & $\mathrm{B}$ & $\mathrm{Si}$ & $\mathrm{Zr}$ & $\mathrm{S}$ \\
\hline 0.47 & 0.31 & 0.35 & 0.083 & 0.015 & 0.014 & 0.001 \\
\hline \hline
\end{tabular}

Bahan dipotong membentuk plat berukuran $(15 \times 10 \times 6)$

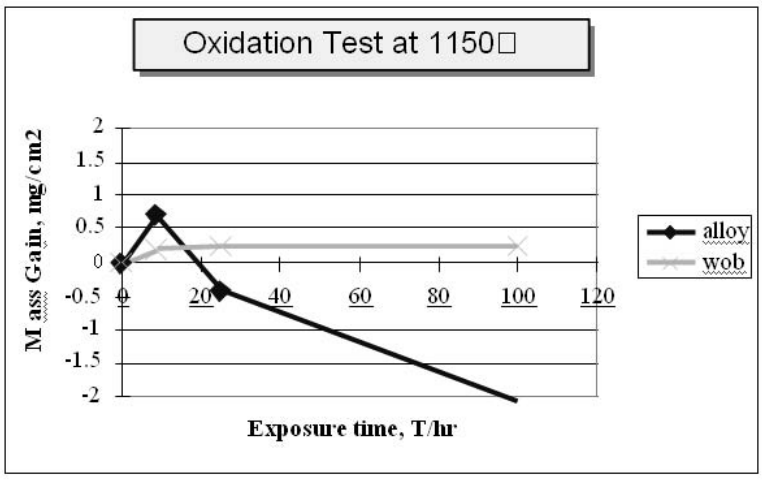

Gambar 4: Grafik berat masa vs lama waktu oksidasi

$\mathrm{mm}^{3}$, untuk keperluan proses electroplating pada bahan dilobangi dengan diameter $1,5 \mathrm{~mm}$ untuk mengingkatkan kawat nikel, dan sampel digosok dengan kertas ampelas nomor 150 diteruskan dengan pencucian dengan agitasi ultrasonic dalam methanol benzen. Adapun proses pembentukan lapisan alloy $\mathrm{Ni}-\mathrm{Al}$ adalah sebagai berikut.

1. Sample dilapisi lagi dengan Ni-Watts setebal $50 \eta \mathrm{m}$

2. Diteruskan dengan proses $\mathrm{Al}$ pack cementation untuk membentuk lapisan $\mathrm{NiAl}$ sebagai lapisan cadangan $\mathrm{Al}$.

Pada percobaan ini telah disiapkan 2 jenis sample, yaitu sampel berupa bahan substrat saja dan sampel berupa bahan substrat yang dilapisi NiAl saja dan sampel berupa substrat dengan lapisan Ni Al. Test oksidasi dilakukan pada udara statik pada temperatur $1150^{\circ} \mathrm{C}$ selama 600 jam. Pada kedua sample dilakukan penimbangan berat. Struktur mikro lapisan sebelum dan sesudah proses oksidasi diamati dengan EPMA untuk mendapatkan profil konsentrasi masing masing elemen.

\section{HASIL DAN DISKUSI}

Dari hasil tes oksidasi didapatkan bahwa berat sampel alloy sebelum di coating sudah mulai mengalami pengurangan berat setelah 9 jam dan mulai terkelupas setelah 25 jam. Hal ini menunjukkan bahwa rentang waktu 0-9 jam sampel alloy terbentuk lapisan oksida sehingga terjadi kenaikan berat sampel, kemudian dikarenakan serangan oksidasi dan korosi panas yang sangat hebat, sampel mulai terkorosi dan mengelupas, sehingga berat sampel terus berkurang, sebagaimana terlihat pada Gambar 5a.

Sementara itu untuk sampel yang sudah dicoating, dari 025 jam sampel mengalami kenaikan berat yang relatif sedang, kemudian setelah itu kenaikan berat sampel sangat sedikit bahkan cenderung landai. Hal ini menunjukkan pada sampel hanya timbul lapisan oksida saja, dan lapisan ini cukup stabil sampai berakhirnya tes oksidasi. Timbulnya lapisan oksida ini berasal dari reaksi oksidasi $\mathrm{Al}$ dari fase $\mathrm{NiAl}$ pada bagian eksternal yang memang kaya akan Al. Akan tetapi jika dilihat Gambar 5b terlihat ada sedikit serpihan dari kerak lapisan oksida pada sampel yang terkelupas. 

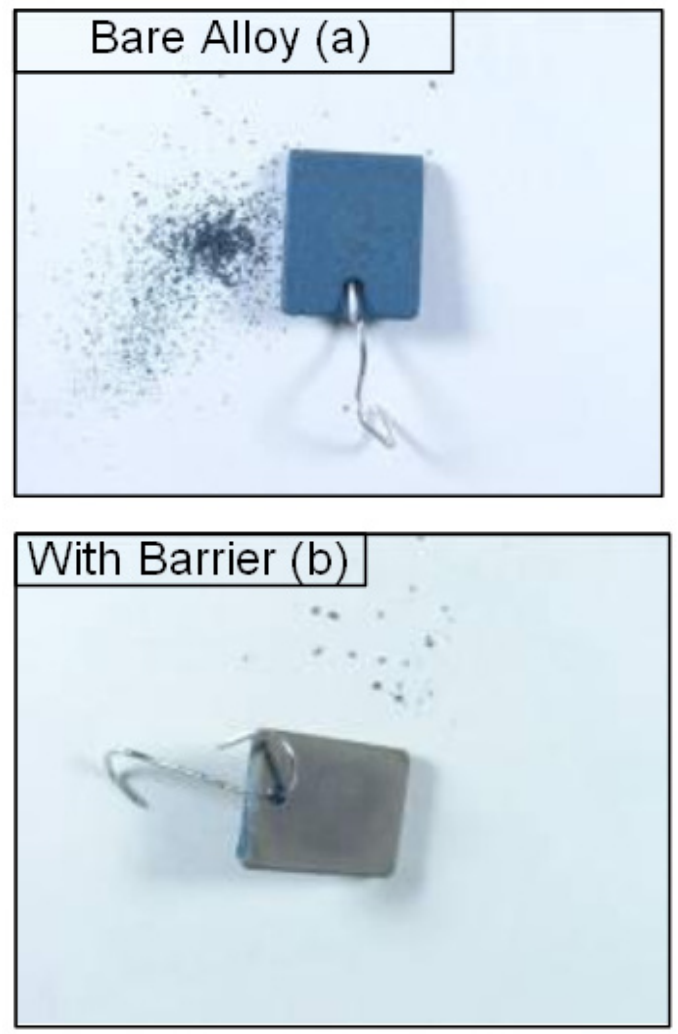

Gambar 5: Foto makro dari sampel sebelum coating (a) dan sesudah coating (b) setelah tes oksidasi.

Jika diperhatikan lebih lanjut, pada bagian atas substrat terlihat timbul banyak topologically closed packed (TCP) yang dapat mengurangi sifat mekanis dari substrat. Timbulnya TCP ini kemungkinan diakibatkan oleh proses oksidasi yang menyebabkan perubahan komposisi kimia pada substrat, sehingga timbul suatu fasa baru dan memang pada paduan super Ni dan $\mathrm{Co}$, di mana keduanya merupakan paduan yang metastabil, lebih mudah timbul fasa TCP dan ini merupakan salah satu kelemahan dari kedua paduan tersebut, sebagaimana yang dikatakan Henry L. Bernstein [6]. Dan di bagian internal dari lapisan coating $\mathrm{NiAl}$ terjadi perubahan fasa dari $\beta \mathrm{NiAl}$ menjadi $\beta+\gamma^{\prime} \mathrm{NiAl}$.

Dari hasil analisa EPMA pada Gambar 7a dari sampel yang sudah dicoating dan setelah tes oksidasi, dapat diketahui bahwa pada bagian eksternal dari lapisan coating $\beta$ $\mathrm{NiAl}$,sebagian besar berupa oksida dan $\mathrm{Al}$, kemudian ada $\mathrm{Ni}$ dan sebagian kecil lainnya berupa $\mathrm{Co}, \mathrm{Cr}, \mathrm{W}$, Ti dan Re. Jika dilihat lagi pada Gambar 7c, pada komposisinya terdapat juga Hf.

Sementara itu pada bagian internalnya, komposisinya sebagian besar berupa $\mathrm{Ni}$ dan $\mathrm{Al}$, dan sebagian kecil lainnya berupa Co, Cr, W, O, Ti, Ta dan Re. Pada bagian ini tidak ditemukan adanya unsur Hf, sebagaimana pada bagian eksternal.

Untuk substratnya sebagian besar komposisinya berupa Ni, $\mathrm{Al}, \mathrm{Cr}$ dan Co. Dari gambar tampak bahwa dengan semakin lamanya waktu oksidasi, Al cenderung menurun, sementara
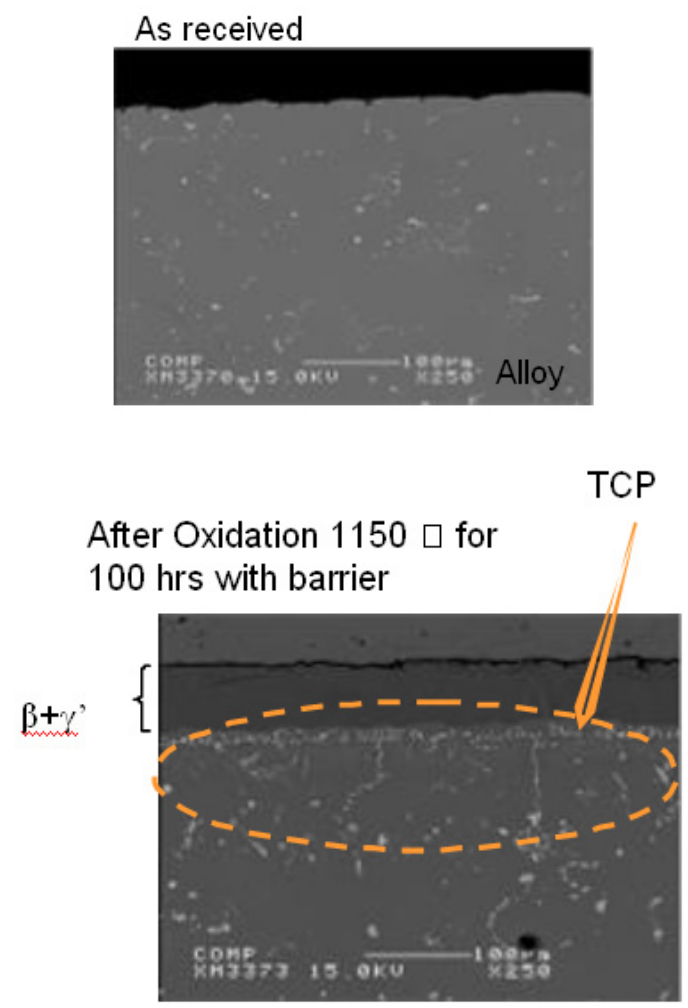

Gambar 6: Foto struktur mikro dari sampel alloy (kiri) dan sampel yang sudah dicoating (kanan)sesudah tes oksidasi

itu $\mathrm{Cr}$ dan Co cenderung naik. Hal ini menunjukkan bahwa unsur $\mathrm{Al}$ setelah terdifusi ke luar membentuk lapisan oksida $\mathrm{Al}_{2} \mathrm{O}_{3}$, jug a terdifusi ke substrat. Sementara unsur $\mathrm{Cr}$ dan $\mathrm{Co}$ pada substrat tampak terdifusi ke arah permukaan, hal ini dapat diketahui dari adanya unsur $\mathrm{Cr}$ dan $\mathrm{Co}$ pada bagian internal dan eksternal lapisan coating NiAl. Adanya unsur-unsur seperti W, Ti, Ta, Re dan Hf pada bagian eksternal, menunjukkan unsur-unsur solid solution hardening itu ikut berdifusi sampai ke permukaan, di mana hal ini ditunjukkan pada Tabel 2, komposisi kimia dari bagian eksternal, kaya Al, setelah tes oksidasi.

TABEL II: Komposisi kimia dari bagian eksternal, kaya Al, setelah tes oksidasi

\begin{tabular}{cccccccccc}
\hline \hline $\mathrm{Al}$ & $\mathrm{Cr}$ & $\mathrm{Co}$ & $\mathrm{Ni}$ & $\mathrm{Zr}$ & $\mathrm{Mo}$ & $\mathrm{Hf}$ & $\mathrm{Ta}$ & $\mathrm{W}$ & $\mathrm{Re}$ \\
\hline 76.2 & 1.4 & 0.7 & 21.4 & 0.04 & 0.01 & 0.10 & 0.1 & 0.06 & 0.05 \\
\hline
\end{tabular}

Untuk komposisi kimia dari fasa TCP pada bagian sebelah kiri, urutan komposisinya sebagian besar berupa $\mathrm{Ni}, \mathrm{W}, \mathrm{Cr}$, Co dan Al. Pada fasa ini terlihat unsur Ni komposisinya jauh lebih rendah jika dibandingkan pada bagian substrat lainnya, dan unsur W dan Cr naik cukup tinggi jika dibandingkan lainnya. Pada fasa TCP lainnya yang disebelah kanan dari fasa TCP sebelumnya, unsur Ni juga mengalami penurunan, meski lebih sedikit sebelumnya, dan unsur $\mathrm{W}$ juga sedikit ikut naik, juga diikuti oleh Cr. Kemudian jika dibandingkan lebih lanjut 

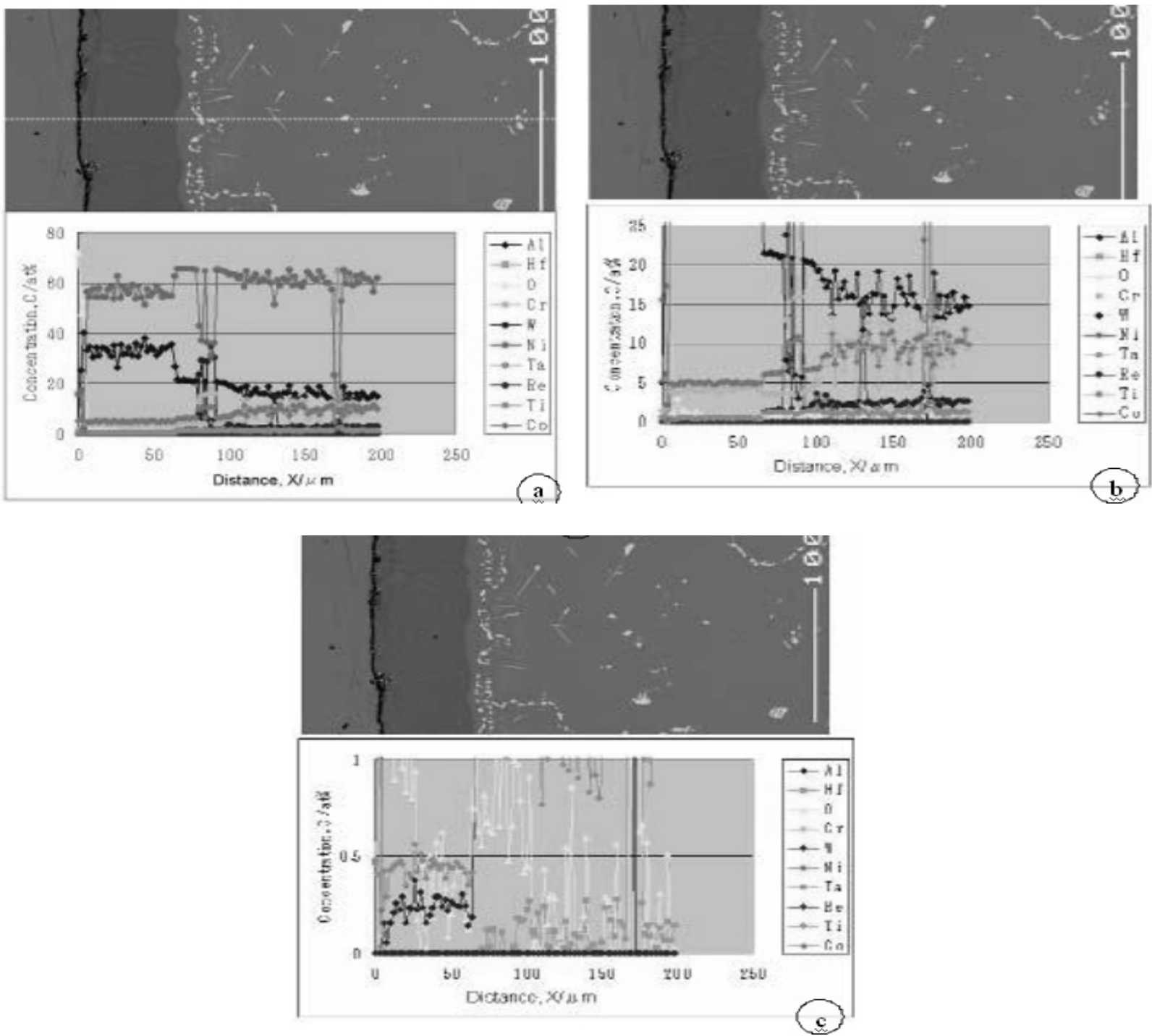

Gambar 7: Komposisi kimia sampel yang tercoating dan setelah tes oksidasi, 7a) untuk 100\% atom komposisi, 7b) untuk $25 \%$ atom komposisi dan $7 \mathrm{c}$ ) $1 \%$ atom komposisi

pada fasa TCP di bagian tengah, di mana urutan komposisinya sebagian besar berupa Hf, Ti dan Ni.

Sedangkan untuk yang lain masing-masing besarnya di bawah 5\%at. Kejadian ini menunjukkan adanya persamaan bahwa setiap adanya fasa TCP, maka di titik itu terjadi penurunan Ni. Adanya $\mathrm{W}$ yang diikuti $\mathrm{Cr}$ dan $\mathrm{Hf}$ merupakan solid solution hardening yang metastabil, cenderung ingin kembali ke fasa yang stabil.

\section{SIMPULAN}

Telah dilakukan thermal barrier coating (TBC) bond coat pada paduan khusus berbasis Nikel dengan proses elektroplating $\mathrm{Ni}$ watts dan proses pack-cementation $\mathrm{Al}$ dengan media serbuk alumina. Hasil pengujian pelapisan dengan tes oksidasi di udara statis pada temperatur $150^{\circ} \mathrm{C}$ dan analisa pro- fil elemen kimia sebelum dan sesudah oksidasi menunjukkan bahwa:

1. Lapisan coating $\mathrm{NiAl}$ telah mampu menahan laju oksidasi dan korosi panas sehingga sampel setelah uji oksidasi masih dalam kondisi yang baik.

2. Pada penelitian ini masih tampak adanya difusi unsur $\mathrm{Cr}$ dan Co, juga unsur-unsur yang kecil lainnya ikut berdifusi sampai ke permukaan lapisan coating. Dan unsur Al yang ikut berdifusi ke substrat.

3. Pada penelitian ini juga masih timbul adanya fasa topologically closed packed (TCP) yang dapat menurunkan sifat mekanis dari substrat dan menimbulkan nantinya awal patahan. 
[1] J. P. Singh, dkk, Damage Evolution And Stress Analysis In Zirconia ThermalBarrierCoatings During Cyclic And Isothermal Oxidation, Journal of the American Ceramic Society, 84(10) 2385-93 (2001))

[2] http://www.msm.cam.ac.uk/phase-trans/2003/Superalloys/ coatings/ aluminides.html, 24/04/07; 08:03.

[3] http://www.msm.cam.ac.uk/phase-trans/2003/Superalloys/ coatings/ index.html, 24/04/07;08:15.

[4] Z. Yu, dkk, NiAl bond coats made by a directed vapor deposi- tion approach, Materials Science and Engineering, A 394, 4352(2005)

[5] D. Coutsouradis et al., eds. (Appl. Sci. Pub., London, 1978)

[6] Henry L. Bernstein, 2006, http://turbolab.tamu.edu/pubs/ Turbo35 / T3504ASME.pdf, 24/04/07, 03:59

[7] http://www.tms.org/Meetings/Specialty/Superalloys2000/ SuperalloysHistory. html,23/04/07; 0915. 